\title{
ANALYSIS OF AXLE SHAFT FATIGUE FAILURE AND ANTI-FATIGUE SYSTEM DESIGN
}

\author{
Gurkan Irsel ${ }^{1}$ \\ 1 Trakya University, Faculty of Engineering, Mechanical Engineering Department, 22180, Edirne, Turkey, e-mail: \\ gurkanirsel@trakya.edu.tr
}

Received: 2017.05.15

Accepted: 2017.08.01

Published: 2017.09.03

\begin{abstract}
In this study, an axle shaft subjected to static deformation and fatigue damage was considered by using computer-aided engineering. This shaft system was modeled with CATIA and subjected to dynamic fatigue analyses with Ansys workbench. The damaged fracture surfaces of the shaft have been examined. Thus, the fatigue and damage was revealed in greater detail. For the present system, a design with a minimum cost, short production process, minimum weight was sought together with methodical construction principles. By means of CATIA and ANSYS, the product development design with reasonable tension and deformation values was formed for endless life fatigue. A design was produced in a short space of time with the help of 2D CATIA drawings and field tests were carried out. The design was used through 560.000 cycles and damage was not observed.
\end{abstract}

Keywords: CATIA, ANSYS, fatigue analysis, re-design, shaft fatigue, product development.

\section{INTRODUCTION}

The shaft is an important supporting and power transmission element used in machine and mechanical equipment. In this study, an axle shaft broken by fatigue damage was examined. Axles are forced to bend and cut under radial force. Even though they are rarely forced against tension or pressure, they are never forced to twist. The axles used are fixed or rotary. It is the machine parts that are used for bedding of stationary, swinging or rotating elements [10]. The shaft examined in this study was used for bedding of Cambridge type rolls that form pressure by rotating on agriculture land. This shaft was subjected to static deformation and fatigue damage during operation. Shaft damage carried out in the form of fatigue, static bending deformation, fatigue, respectively.

Fatigue is the damage that formed because of repetitive stretching of the material or unit shape changes. Except for special cases, the tension lev- el, which mostly causes fatigue, is smaller than the yield strength of the material. Fatigue is very complex and only a partially understood issue. The surface characteristics of damaged metallic objects that showed damage in the areas are directly related to the ambient conditions the material is working under. Therefore, in the analysis of the cause of damage formation, the fracture surfaces and the shaft surface cracks near the surface are examined. On the surface, the fatigue center where cracks started and the same centered curves that are similar to mussel shell surrounding it and next to these a grain zone is seen. As the crack progresses slowly over time, because of friction between the opposing surfaces, the surface of the fatigue fracture appears brighter. When the crack progresses and the remaining full section becomes unable to carry the normal load, a sudden fracture occurs and the fracture surface looks granular. There are many things to learn from the patterns of cracks in fatigue damage. Schematic 
illustrations of fatigue-cracking surfaces that occur in structures with smooth and notched elements with circular and rectangular sections at different loading and nominal tension levels are published in many books and catalogs [3].

Complex mathematical models of fatigue can only be solved by computer aided engineering. Today's industry is focused on computer-aided analysis to design, develop and optimize a shorter product development cycle, faster marketing process, and reliable and durable products [17]. The emergence of faster computers and powerful FEA software provides design engineers the ability to create larger, more refined and complex models and thus it enables customers to produce on time cost-effective, accurate and informative solutions to their problems. Stress and fatigue life is successfully calculated in a short time with structural analyzes under varying load conditions. $\mathrm{K}$. Thriveni and Chandraiah [19] studied the static stress analysis on a crankshaft. They modeled the crankshaft using CATIA-V5 software. By using Finite Element Analysis (FEA), ANSYS software, they examined the stress variation at critical locations of the crankshaft model. Panda and others made Rims modeling by using Catia V5 R18 software. They transferred this CATIA model to ANSYS for analysis work. They used ANSYS software to calculate and display stress values generated by the applied forces. They made stress analyzes for two different alloys, such as aluminum and magnesium alloys. Shaik Gulam Abul Hasan et al. [8] in their work have designed on the basis of each components safety factors. In this study, the model was transferred to ANSYS. First, they made a static analysis of the model. The limit conditions and the model have thus been studied. Then dynamic analyzes of gears were revealed by modal analysis. T. Siva Prasad et al. [15] made rims designed using CATIA v5 R17 software in their study. They transferred the model to ANSYS and revealed aluminum and forged steel performances by static and dynamic analysis. Yao et al. [21] shortly reviewed anti-fatigue design approaches in their work. The approaches that were classified in three groups are the nominal stress approach, the local stress-fatigue approach and the stress area density approach. Two specially designed 30 specimens, each with two notches, were tested under different constant amplitude loads. They analyzed the samples by elastoplastic FEM to obtain stress-strain distributions and stress concentration factors. We li et al. [11] analyzed the cause of breakage to the crankshaft with an air compressor by chemical composition, mechanical properties, macroscopic properties, microscopic structure and theoretical calculation methods. Fatigue began at the lubrication hole because of high bending stress concentration. The crankshaft fatigue fracture was associated only with the start and the spreading of fatigue cracks in the lubrication hole under cyclic bending and torsion. Espadafor et al. [5] analyzed the crankshaft fatigue fracture damage of a diesel engine operating at nominal $1500 \mathrm{rpm}$. The engine running at full load has served 20,000 hours. They reached the conclusion that fatigue defines the benchmarks clearly. Ankit Basnet et al. [2] made an optimization study in this article to reduce the weight of the crankshaft. Here, the shaft was modeled using Catia V-5 and analyzed in ANSYS 16.0. A. Goksenli and Eryurek I.B. [7] studied the fatigue damage of an elevator drive shaft that was used for 30 years and analyzed it in detail. They identified microstructural, mechanical and chemical properties of the shaft. They visually searched the fractured surface. Osman Asi [1], in his study, explained the fatigue damage analysis of an automobile axle shaft of the rear axle. As a result of the damage, he found that the axle shaft was divided into two parts. The study was done to determine whether the cause of the damage was a result of fatigue damage. An evaluation was made to assess the integrity of the damaged axle shaft, including visual inspection, photo documentation, chemical analysis, micro hardness measurement, stress testing and metallographic inspection. Damage levels were examined by electron microscopy. In the study done by Fonte et al. [6] it was suspected that most of the mechanical failures in the rotor shaft are under constant torsion and bending. They briefly presented the analysis about fatigue cracking on shafts, the effect of constant torsion loading on crack growth rates. For two types of tests, they performed long cracks growth tests on cylindrical specimens for Ck45 material. Fixed torsion and combined alternative bending were applied to imitate the real conditions on the power rotor shaft. Starting from the cylindrical sample surface, semi-elliptical surface cracks and various loading conditions were measured for both tests. Sh. Zangeneh et al. [22] explored the fracture damage analysis of a mixer shaft inside a large boat. This analysis method focused on fractured surface analysis and finite element method (FEM) simulation. They used 
Abaqus software for tension analysis. Om Parkash et al. [14] re-optimized the current design of the tie rod on the Universal brand tractor (U650), by changing some design variables. They performed modeling of the current design. Under fatigue load, they evaluated the critical areas in the tie rod. In the current study, the model was developed, analyzed and designed by using CATIA 19, PRO-E and ANSYS v12. The purpose of this article that was performed by Anupam Raj Jha et al. [9] is to design and analyze structural deformations in an articulation joint. The system was designed by using CATIA V5 and analyzed in ANSYS Workbench 14.5. In Mr. Sasank Shekhar Panda's at al. [13] Simulation study, he performed modeling by using CATIA and performed Software, Static and Fatigue analyzes by using ANSYS software. Surekha S. Shelke et al. [16] in this article, they performed static structural analysis on a 2-cylinder crankshaft by using ANSYS. They transferred 3D models of the crankshaft to ANSYS, which is mainly analyzed for stress, deformation and fatigue. The analysis results are used to determine the life of the crankshaft and to optimize the design $[18,20]$.

As you see, the appearance of the fracture surfaces has an important place in many studies. Analysis of fatigue with computer-aided engineering programs such as CATIA is common. CATIA is used as the first step in the formation of CAD data in many studies. Ansys is preferred especially for performing dynamic analysis. However, a planned and systematic way must be followed to achieve a successful design solution. Construction system is the best way to build successful and productive designs, to redesign by improving of produced designs, and not to experience financial losses $[4,10]$.

The main purpose of this study is to examine shaft fatigue phenomenon exposed to static deformation and dynamic fatigue damage. To put forth a new design system of anti-fatigue analysis and to produce and evaluate this design. In this context, the current system with damaged shaft was modeled with CATIA. The damaged fracture surfaces of the shaft were examined. The shaft solid model (in the deformed state) was analyzed by ANSYS dynamic fatigue analysis. The formation of the damage was presented in detail. For the current system, anti-fatigue design, minimal cost, short production process, minimal weight and the new design solution modular were revealed by the methodical construction principles. In this solution,

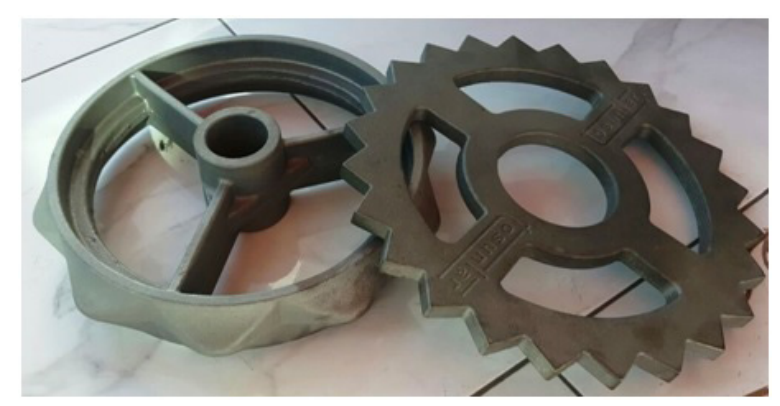

Fig. 1. Cambridge type roller unit

by the help of transferring the CATIA 2D drawings to the plasma cutting table, the system was produced in a short time and field tests were carried out. The results are presented in tables and figures.

\section{MATERIALS AND METHODS}

\section{Identification of Existing System}

The axle shaft examined in this study beds 22 Cambridge type roller units. A roller unit has two main elements. The first is the roller with more oval gears in contact with the shaft (which can be seen in Fig. 1 on the left) and the other one is the shaft with frequent and pointed gears that does not touch the shaft. The total weight of the roller unit is $22 \mathrm{~kg}$ with an outer diameter of $38 \mathrm{~cm}$. and a width of $90 \mathrm{~mm}$.

The examined shaft that suffered fatigue damage is $50 \mathrm{~mm}$ in diameter. The shaft-mounting diameter of the rollers mounted on this shaft is $55 \mathrm{~mm}$. The roller with sharp gear teeth is not

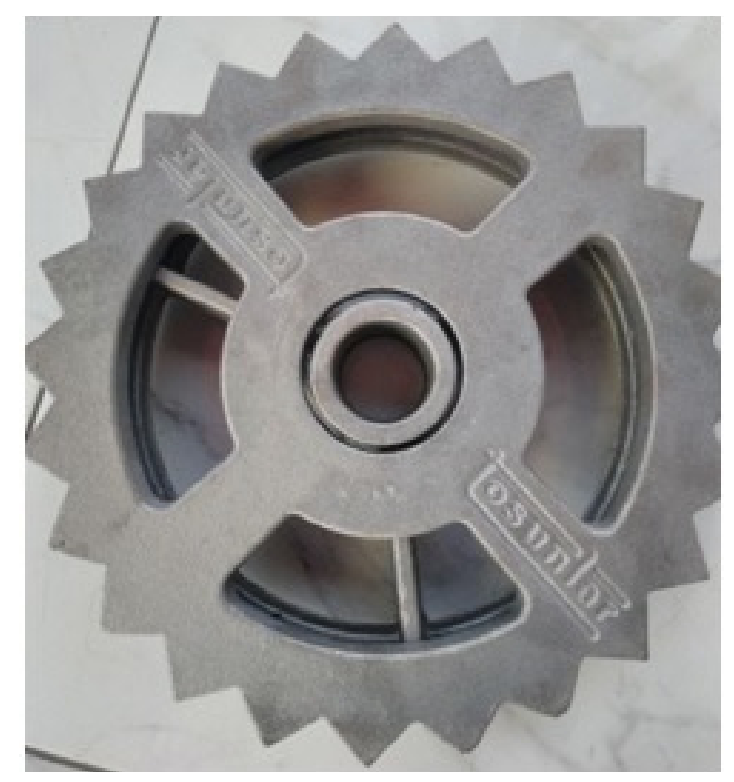

Fig. 2. Installation of the roller unit 


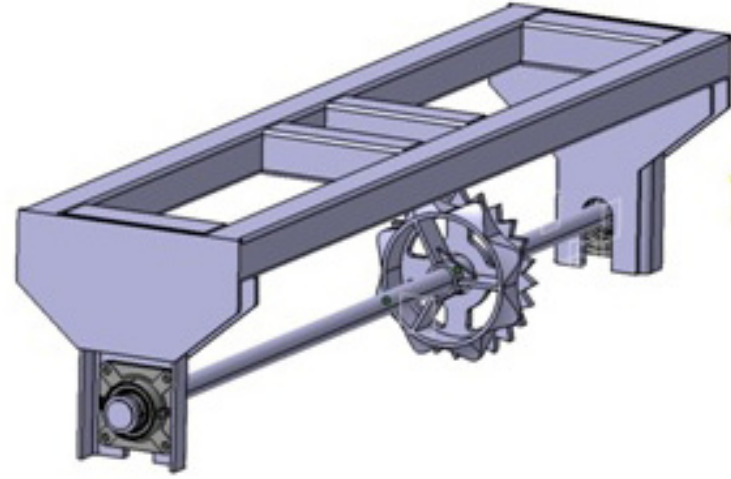

Fig. 3. Roller carriage chassis, beds and a roller unit

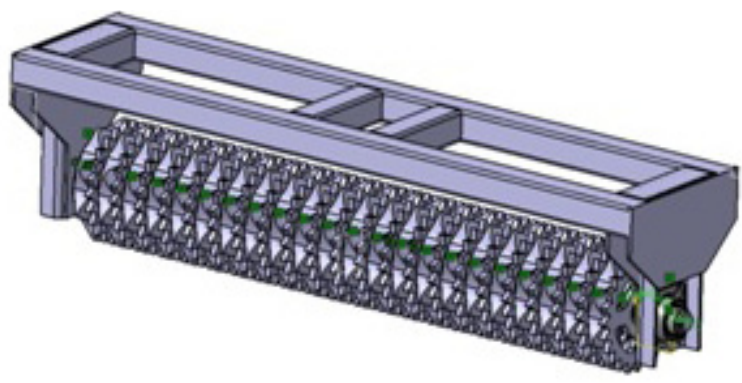

Fig. 4. Pre-damage system solid model

exposed to the shaft and its inner diameter is 80 $\mathrm{mm}$. The roller with narrow sharp gears moves with $5 \mathrm{~mm}$ spaces on the hollowed shaft of the large roller (Fig. 2).

The system where shaft fatigue damage was formed is modeled with CATIA software. The mounting of a roller unit with a shaft of $50 \mathrm{~mm}$ diameter is shown in Fig. 3. It was supported with a flange-bearing unit from the shaft end who's parts are 2.4 meters long. In the case of the roller system chassis, assemblies are seen. Fig. 4 shows the current system. There are 22 roller units on the shaft.

\section{AXIAL SHAFT FATIGUE DAMAGE}

Due to fatigue damage, the surface damage that deepens along the axis of the shaft is revealed. This ductile is the appearance of a fatigue fracture. Fig. 5 shows the benchmarks.

A: fatigue-bending axis. B: indicates tearing in the perpendicular direction to the axis of fatigue. C-fracture area.

The fatigue damage was analyzed for four different situations that the shaft faced until damage occurred.

Case 1 - Analysis of shaft stress when the roller does not contact the floor:

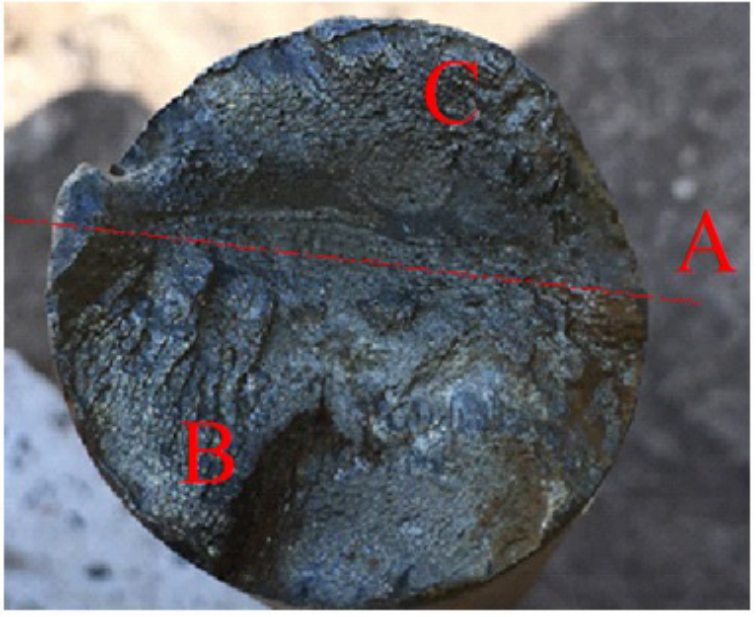

Fig. 5. Shaft fatigue $\&$ surface damage

There is no rotation of the shaft in this case. Fig. 6 shows the cross-section of the roller system. The rollers touch the top part of the shaft, along the red line $(\mathrm{Fa})$. Fl: It is the lifting force applying to the shaft. Here, Fm is the weight effect of the rollers. Sw is the weight of the shaft and is $37 \mathrm{~kg}$.

FI, in the road condition was taken as support. In case of Fa's support, there will be no bending of the shaft. Sw $=370 \mathrm{~N}, \mathrm{Fm}=4840 \mathrm{~N}$. Fa $=\mathrm{Fm}+$ Sw. Fa $=5210 \mathrm{~N}$. In the static analysis carried out in the road condition, the maximum stress was obtained as $68.95 \mathrm{MPa}$ (Fig. 7) and the maximum deformation was calculated as $2.04 \mathrm{~mm}$ (Fig. 8).

Case 2 - Dynamic stress and fatigue analysis in the case of general working:

The rotation speed of the roller system was accepted as $150 \mathrm{rpm}$. The forces acting on the shaft are shown in Fig. 9, in the section of the roller system. Fc is the weight of the entire roller system (pressure force) and Fr is the ground contact reac-
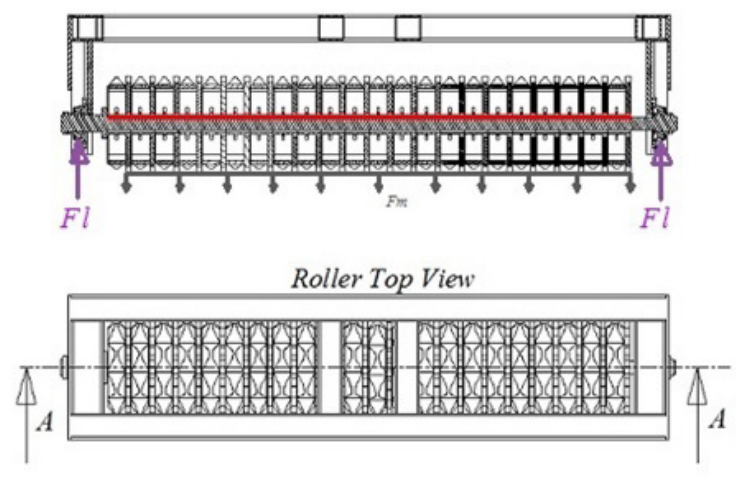

Fig. 6. Extensive loading on shaft 


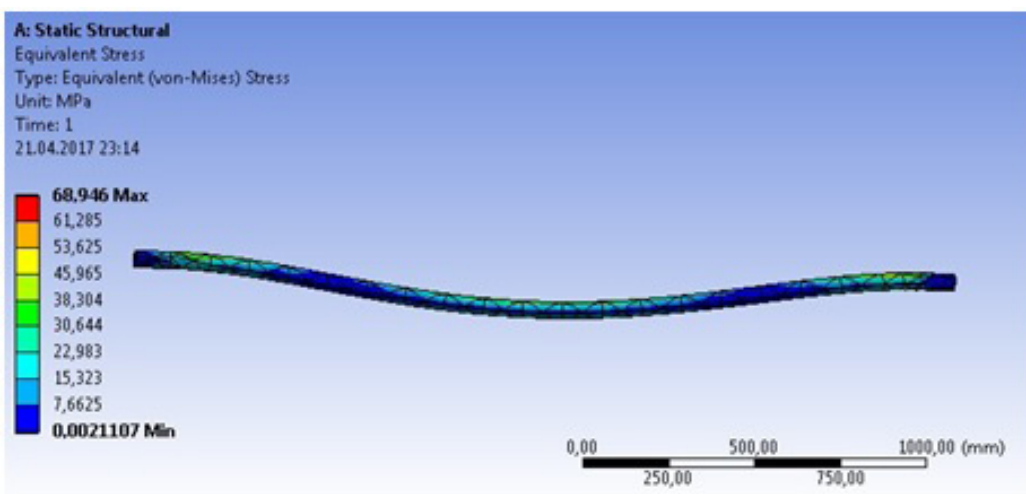

Fig. 7. Maximum stress in shaft in the road condition

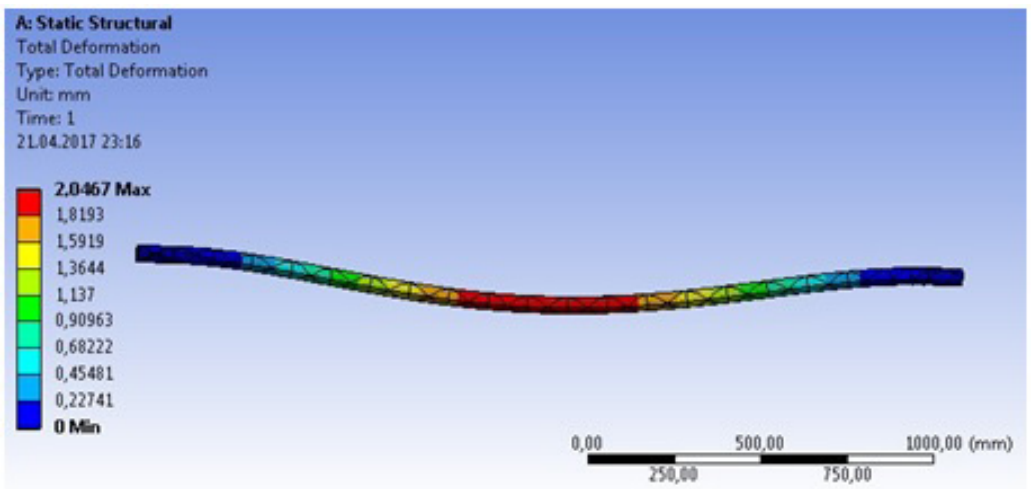

Fig. 8. Maximum deformation in the shaft in the road condition

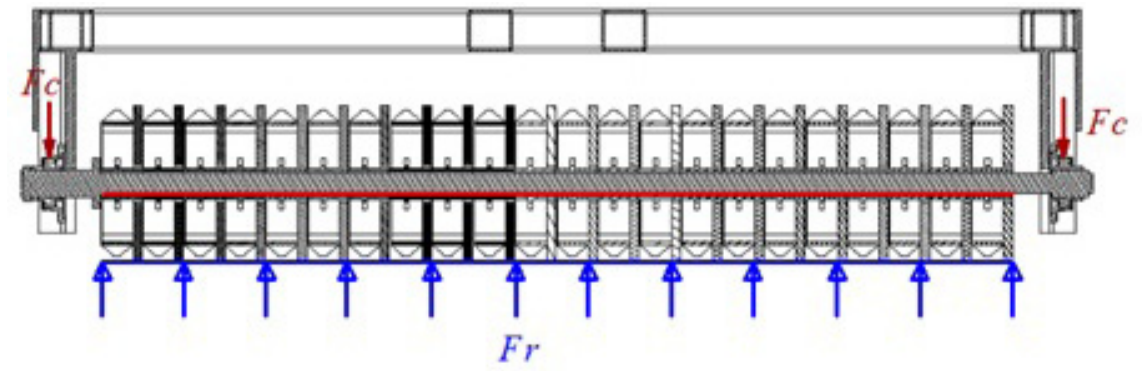

Fig. 9. Cross-sectional view of the general working state of the roller system

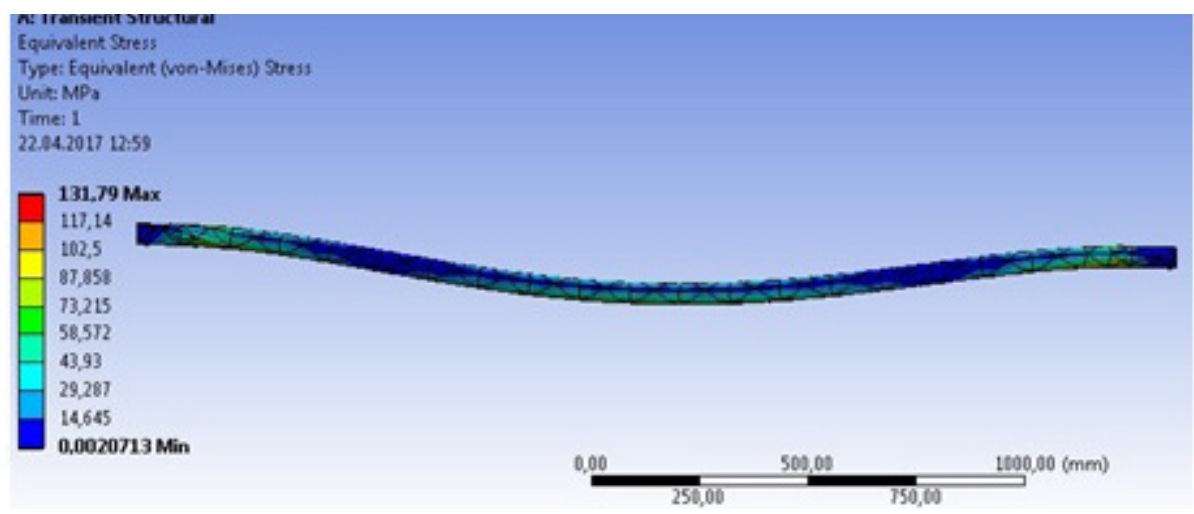

Fig. 10. In the case of general operation, shaft dynamic fatigue analysis: Von Mises tension 


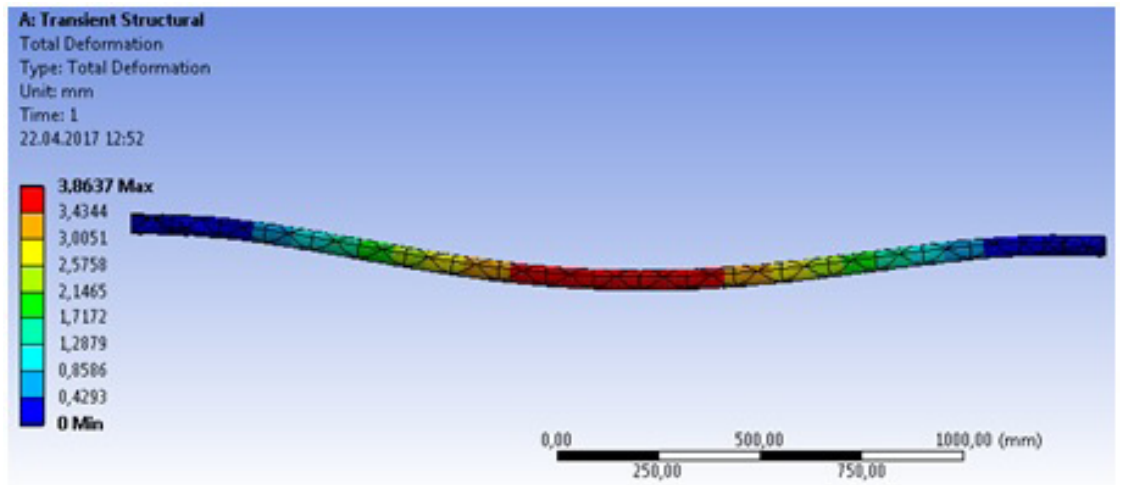

Fig. 11. In the case of general working, shaft dynamic fatigue analysis: total deformation

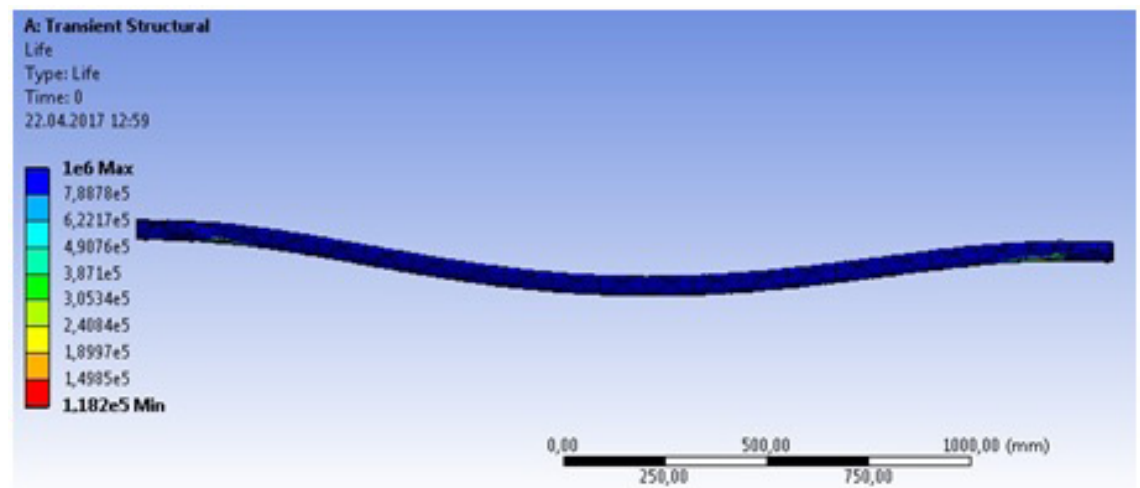

Fig. 12. In the case of general working, shaft dynamic fatigue analysis: life

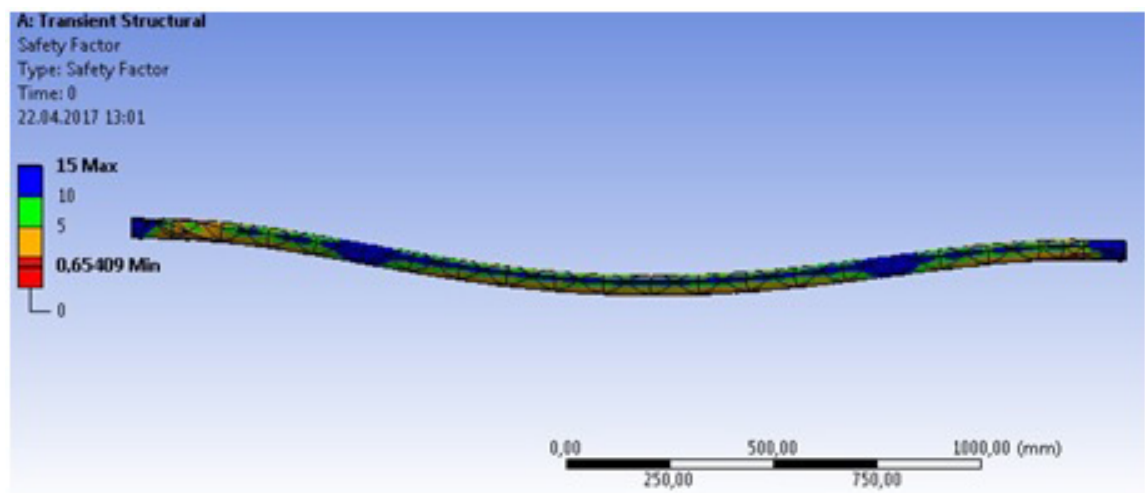

Fig. 13. In the case of general working, dynamic fatigue analysis: safety factor

tion force. $\mathrm{Fc}=\mathrm{Fr} . \mathrm{Fc}=14 \mathrm{kN}$. Fa $=\mathrm{Fr}-\mathrm{Fm}-\mathrm{Sw}$ when $\mathrm{Fc}$ is taken constant. $\mathrm{Fa}=8790 \mathrm{~N}$. In this case, the maximum tension on the shaft is 131,79 $\mathrm{MPa}$ (Fig. 10). The maximum total amount of deformation is $3.86 \mathrm{~mm}$ (Fig. 11). The fatigue life is 118200 cycles (Fig. 12). The Fatigue Safety Factor value is 0.65 as shown in Fig. 13.

Case 3 - Dynamic stress analysis and fatigue analysis in the case of maximum bend- ing load: The "shaft maximum bending loading state" was formed by the forces acting on the shaft is seen in the section of the roller system in Fig. 14. When the system was operated under normal conditions, the shaft hit a hard floor from the center of the shaft by a roller unit that touches the shaft at a width of $9 \mathrm{~cm}$. The shaft was subjected to visible deformation under the influence of these forces (Fig. 14). $\mathrm{Fc}=\mathrm{Fr}=14$ 


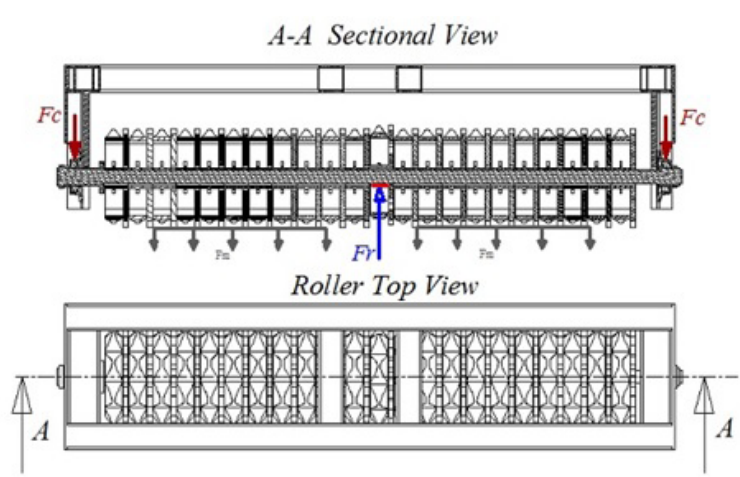

Fig. 14. Shaft maximum bending load, deformation event

kN. Fc was kept constant in the analysis. $\mathrm{Fm}=$ $10 \cdot 22 \mathrm{~kg}$. In this case $\mathrm{Fa}=\mathrm{Fr}-\mathrm{Fm}-\mathrm{Sw} . \mathrm{Fa}=$ $11430 \mathrm{~N}$. The maximum stress acted on the shaft for a short period. This time duration for a speed of $12 \mathrm{~km} / \mathrm{h}$ (roller's forward speed) is $0.075 \mathrm{sec}$ for a $25 \mathrm{~cm}$ hard floor touch. The maximum VonMisses tension strength under these conditions is $296.25 \mathrm{MPa}$ (Fig. 15). The total deformation is $9.41 \mathrm{~mm}$ (Fig. 16).
Case 4 - Dynamic stress analysis and fatigue analysis for deformed shaft geometry:

The amount of deformation of the shaft was obtained by stress analyzes and shaft's approximate deformation measurements were obtained. This measurement was carried out with the optimum combination of broken shaft surfaces and with the help of a gauge. It was considered that the deformation was due to bending of $12 \mathrm{~mm}$ in the middle of the shaft (Fig. 17). Dynamic fatigue analysis was performed with the shaft that was formed in the case of the solid model $12 \mathrm{~mm}$ deformations. $\mathrm{Fm}=18 \cdot 22=396 \mathrm{~kg}$. $\mathrm{Fc}=\mathrm{Fr}=$ $14 \mathrm{kN} . \mathrm{Fa}=\mathrm{Fr}-\mathrm{Fm}-\mathrm{Sw} . \mathrm{Fa}=9670 \mathrm{~N}$. In this analysis, loading was performed at a rate of fatigue damage surface distance (Fig. 5). While the variable loading was acting on the area where bending occurred in the shaft, the ratio was 1 and while it was acting in reverse direction the ratio was accepted as 0.2 (Fig. 18). Dynamic stress analysis and fatigue analysis results for the deformed shaft geometry with Ansys were obtained at a rotational speed of $150 \mathrm{rpm}$. The maximum von-mises stress is $233.88 \mathrm{MPa}$ (Fig. 19). The

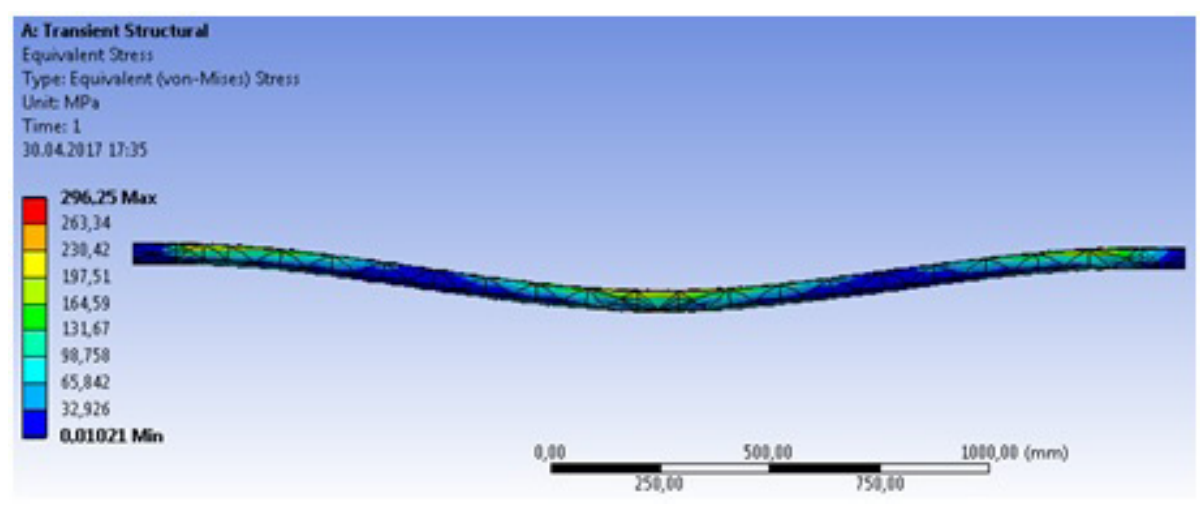

Fig. 15. In the case of maximum bending load: Von -Mises Stress

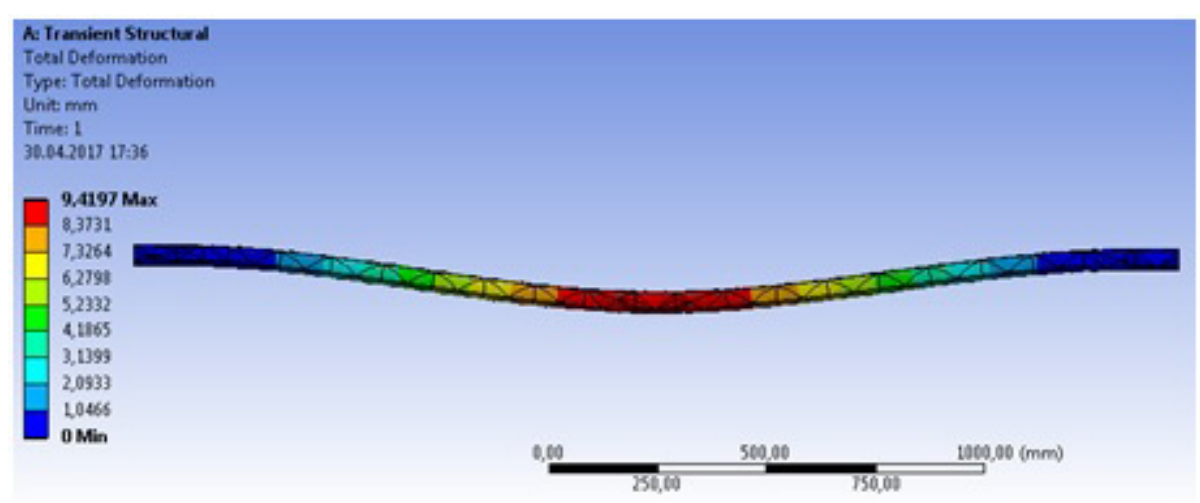

Fig. 16. In the case of maximum bending load: total deformation 


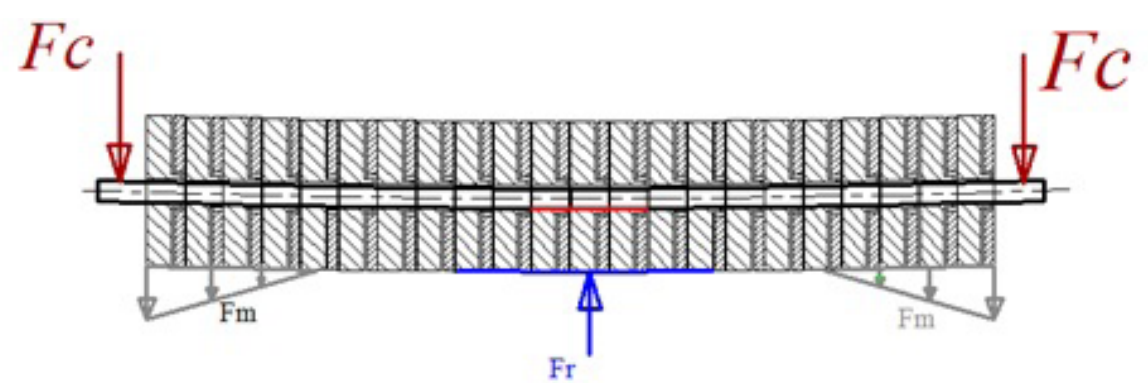

Fig. 17. Loading on deformed shaft

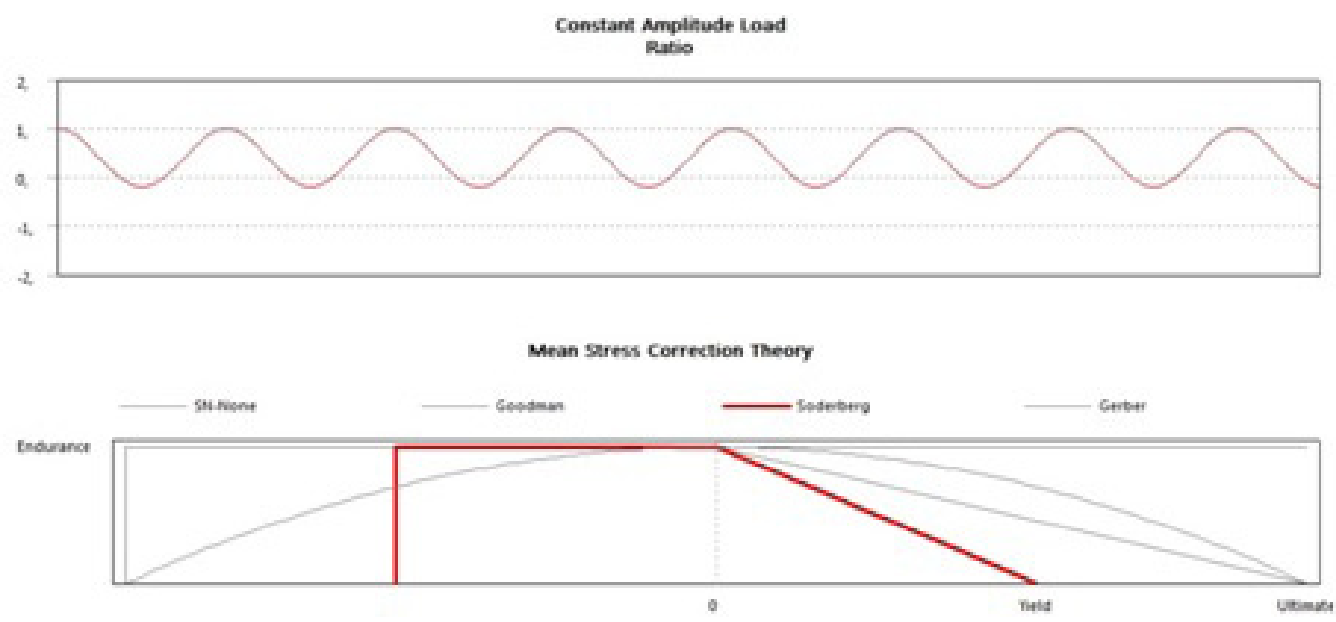

Fig. 18. Variable loading state on deformed shaft

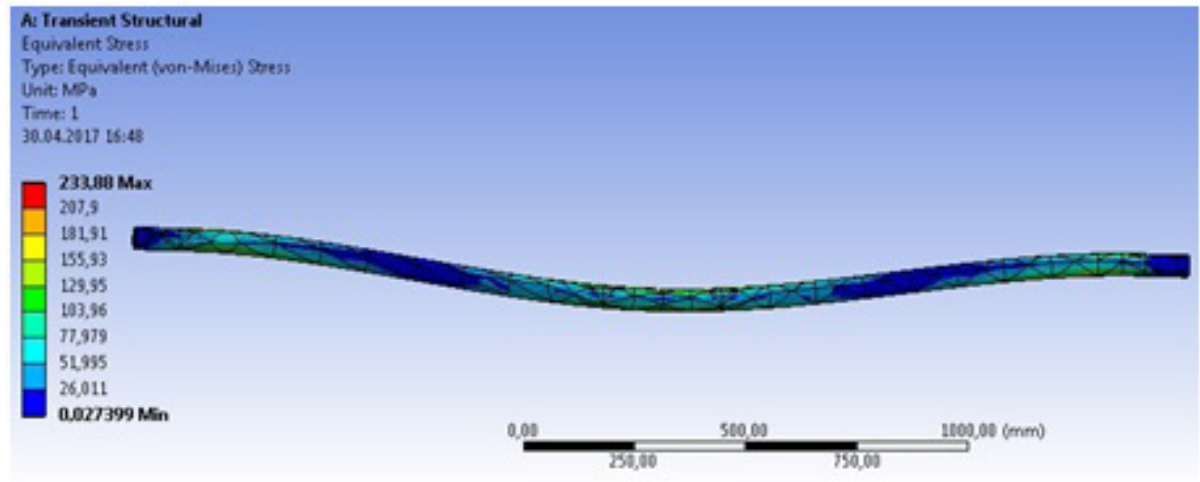

Fig. 19. For deformed shaft geometry: Von Mises stress value

maximum bending deformation is $7.76 \mathrm{~mm}$ (Fig. 20). The fatigue life is 17040 cycles (Fig. 21). The fatigue safety factor value is 0.49 (Fig. 22).

\section{ANTI-FATIGUE AXLE SHAFT DESIGN / PRODUCT DEVELOPMENT}

A planned and systematic approach should be followed to achieve a successful design solution.
This approach is construction systematic Design targets that were determined in this context: production in short time, minimum weight, minimum cost, and modular design. In this context, the shaft was bedded with an additional bearing from the middle. The bed is a circular bearing unit. The ball bearing unit was connected to the plate formed in the plasma-cutting device with four bolts using the $2 \mathrm{D}$ drawing created with $\mathrm{Ca}$ - 


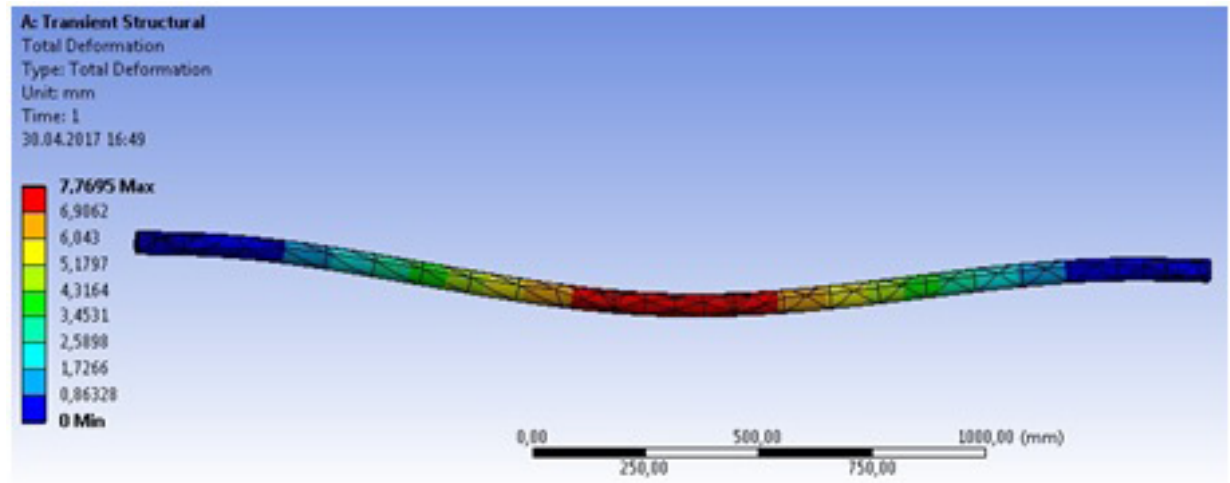

Fig. 20. For deformed shaft geometry: total deformation

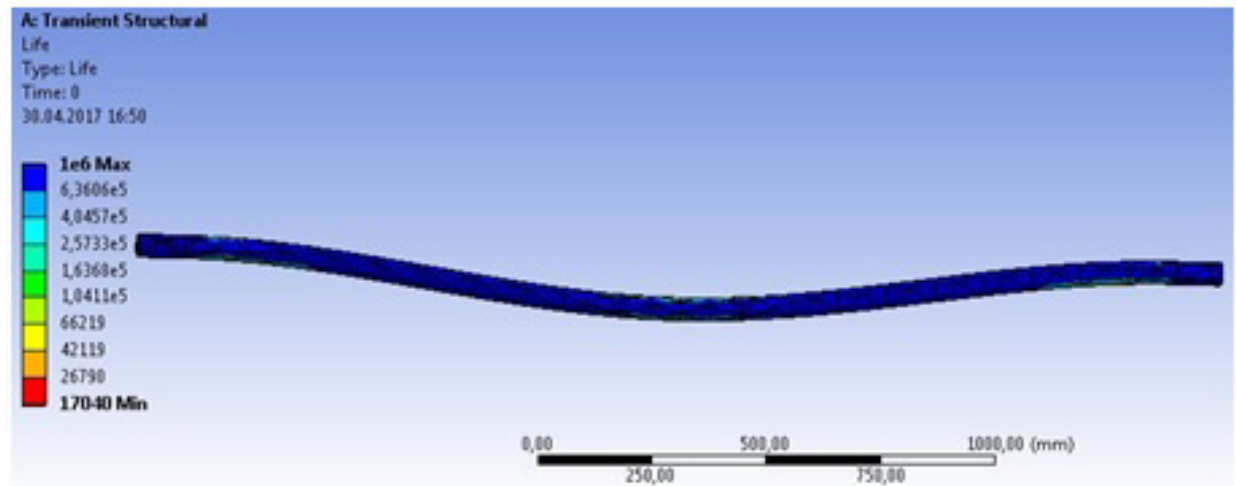

Fig. 21. For deformed shaft geometry: fatigue life

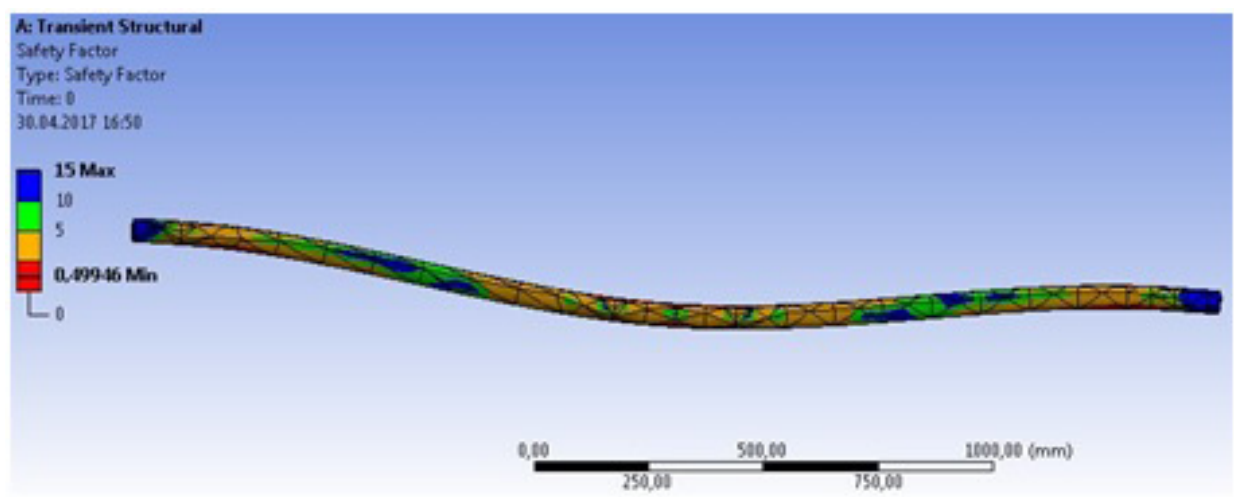

Fig. 22. For deformed shaft geometry: fatigue safety factor

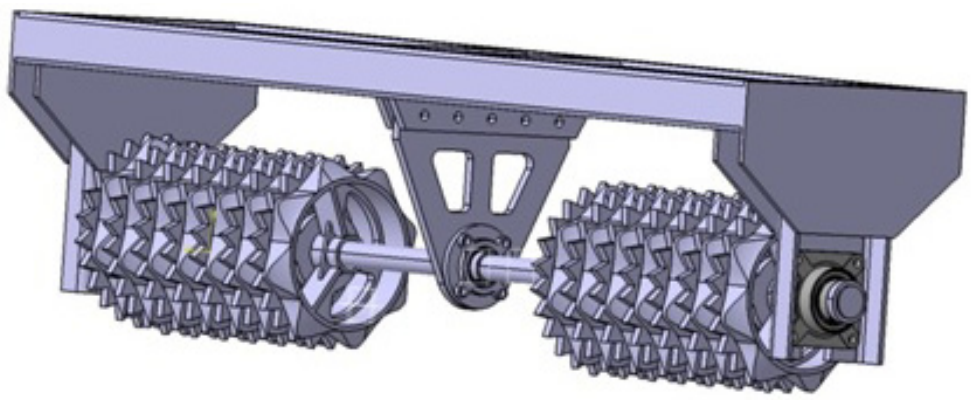

Fig. 23. Roller system improved design assembly 


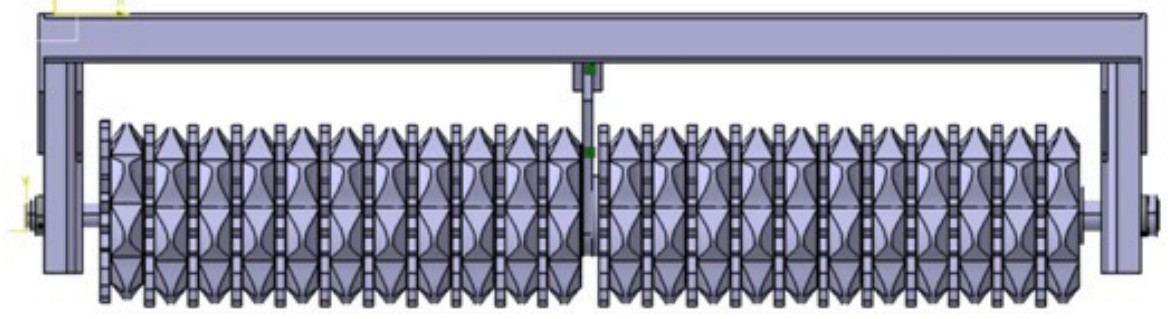

Fig. 24. Roller system improved design assembly section

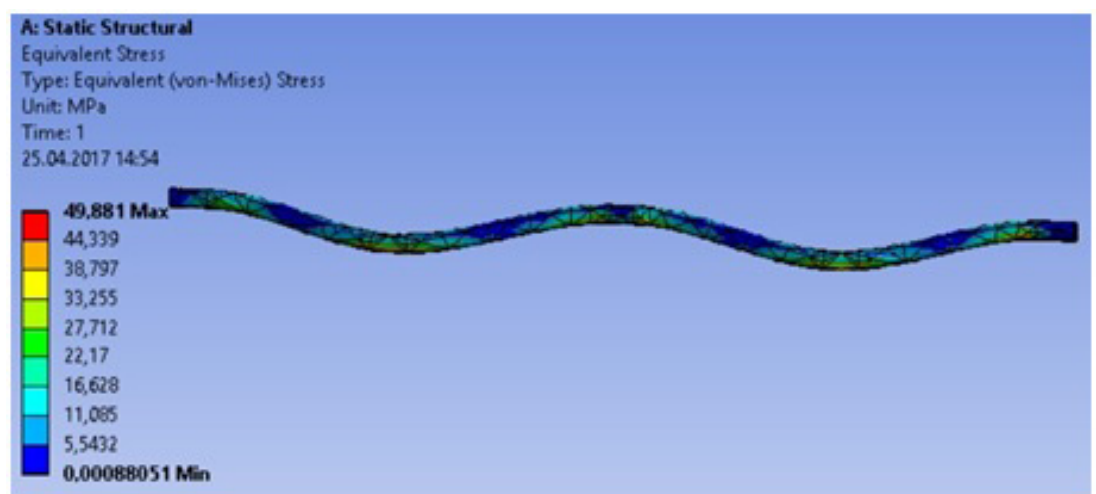

Fig. 25. New anti-fatigue system design: Von-Mises stress value

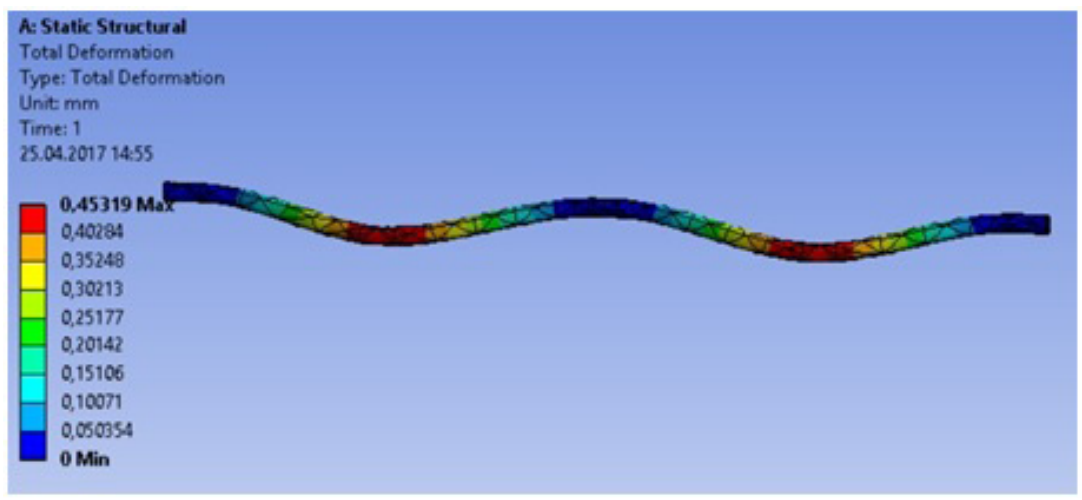

Fig. 26. New anti-fatigue system design: total deformation

tia. The carrier plate is $20 \mathrm{~mm}$ thick and is connected to the chassis with $5 \mathrm{M} 20$ bolts. The formation of the bolt joint ensures that this chassis is used in a different operation. The assembly of the design is shown in Fig. 23. The rollers were hidden in the middle so that the bed design that was created can be clearly seen. Fig. 24 shows the improved roller system assembly sections and forces. $\mathrm{Fa} 1$ and $\mathrm{Fa} 2=4395$.

The maximum von-Mises stress value for a three-bearing system is $49,88 \mathrm{MPa}$ (Fig. 25). The total deformation value is $0,45 \mathrm{~mm}$ (Fig. 26). Fa- tigue life is minimum $1 \cdot 106$ (Fig. 27). The fatigue safety factor value is 1,78 (Fig. 28).

\section{RESULTS AND DISCUSSION}

- Axle shafts are exposed to bending. The fatigue resistance of shafts decreases with bending deformation in the axle shaft.

- The maximum von-Mises stress value, total deformation; fatigue life and safety factor values which were performed with ANSYS for the damaged shaft are shown in Table 1. 


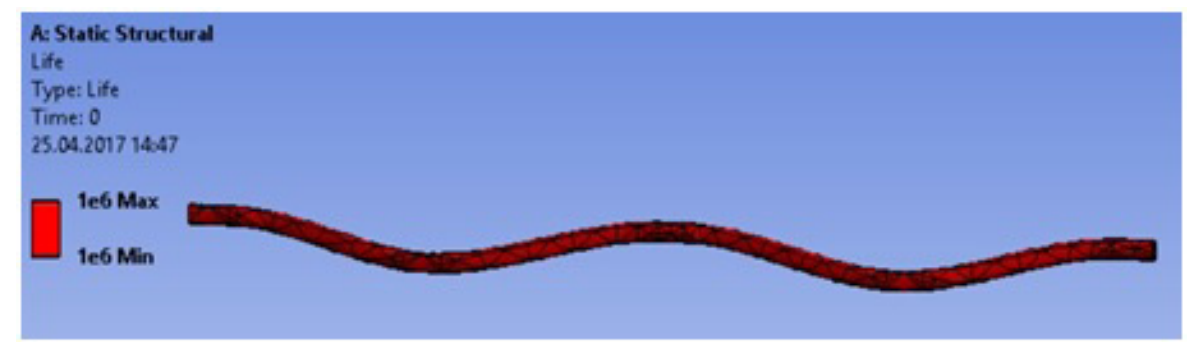

Fig. 27. New anti-fatigue system design: fatigue life

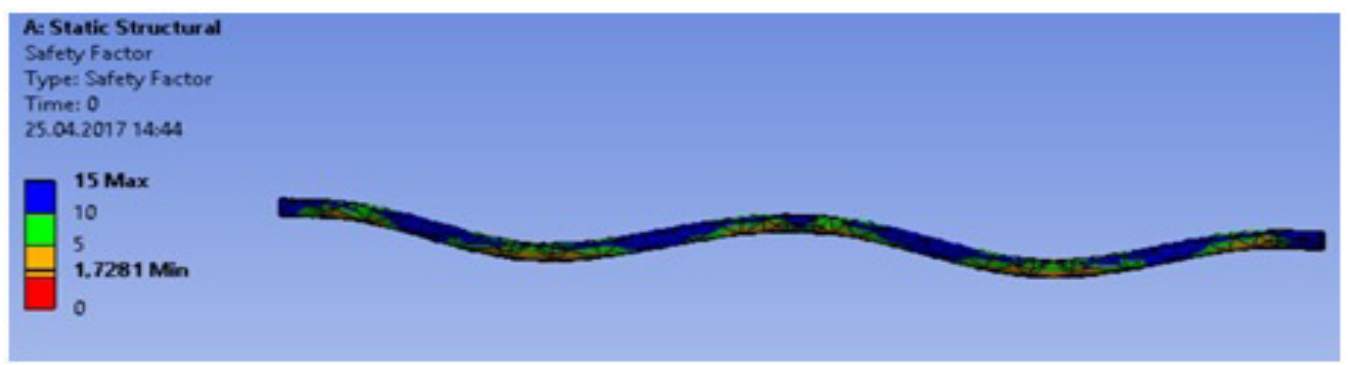

Fig. 28. New anti-fatigue system design: fatigue safety factor

- Case - 1. It is road condition. Stress value and Total deformation values are suitable for St 37 material. In Case - 2, the system is in general operation. Although the shaft is 1.82 times more secure than the maximum stress on it, the fatigue life has a finite value of 118200 . Safety factor value is 0.65 and it is less than one. In Case - 3, the shaft was exposed to very high tension for about 0.75 sec. It has been accepted it was subjected to permanent deformation of $12 \mathrm{~mm}$. In Case4 , the maximum stress is close to the static deformation limit. Here, with a loading rate of one, -0.2 , the fatigue life is 17040 and the safety factor is 0.49 . This is fatigue life for a shaft that has never been exposed to fatigue.

- When the shaft is exposed to deformation damage, the increase in shaft rotation (rpm) increases the fatigue life instead of reducing it. Whereas, the fatigue life in a shaft which a static or dynamic deformation does not occur reduces by the increasing rotation.

- Fatigue Damage happened with the occurrence of Case - 2, Case - 3 and Case - 4 respectively. Case - 2 continued up to about 72000 cycles. In this cycle value (Case - 3 ), the deformation occurred. After the damage, fatigue in the damaged shaft continued for 1240 cycles and damage occurred (Fig. 29). The shaft was broken by bending under the effect of static deformation and fatigue loads.

The system was subjected to deformation at 72,000 cycles $60 \%$ of the total 118200 cycles expected in Case-1. It performed $13 \%$ of the fatigue life calculated in Case- $4.27 \%$ of the fatigue is explained by the fact that there is no linear progressive deformation.

The first case (Case 2) was compared and presented in Table 2 with improved design.

Table 1. Dynamic Stress and Fatigue Analysis Results for Axis Shaft

\begin{tabular}{|c|c|c|c|c|}
\hline & $\begin{array}{c}\text { Von-Mises Max Stres } \\
{[\mathrm{MPa}]}\end{array}$ & $\begin{array}{c}\text { Max Total def. } \\
{[\mathrm{mm}]}\end{array}$ & $\begin{array}{c}\text { Min. Fatigue Life } \\
{[\text { Cycle] }}\end{array}$ & Fatigue Safety Factor \\
\hline Case 1 & 68.94 & 2.04 & - & 3.36 \\
\hline Case 2 & 131.79 & 3.86 & 118200 & 0.65 \\
\hline Case 3 & 296.25 & 9.41 & - & - \\
\hline Case 4 & 233.88 & 7.76 & 17040 & 0.49 \\
\hline Re desgin & 49.88 & 0.45 & $11^{*} 10^{6}$ & 1.72 \\
\hline
\end{tabular}




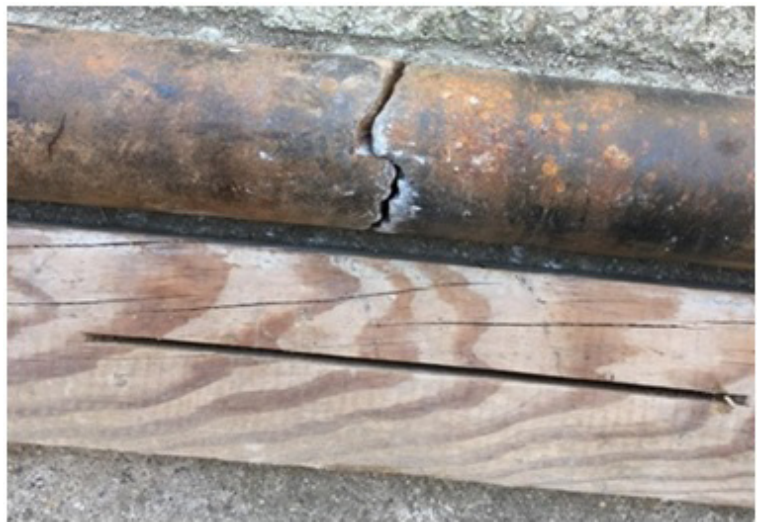

Fig. 29. The shaft broken by bending under the effect of static deformation and fatigue

When Table 2 was examined, it is seen that the performed design provides maximum benefit at minimum cost and minimum weight.

- Fatigue has occurred in the position where the maximum displacement occurred. When the fracture surfaces are examined important information about the fatigue is obtained. This is a bending fatigue as seen from the shafts outer surface cracks. The outer surface cracks have moved towards the center. The ductility of the material exposed to fatigue is clearly understood from the fractured surface. In this study, there are depths of fracture along the axis of the shaft in the examined shaft fracture zone. The small number of benchmarks clearly demonstrates that the post-deformation fatigue damage occurred in a very short time [11]. The high level of bending the shaft is the basic cause of fatigue damage (Fig. 30)

- The data of the computer aided engineering design process is quite important in a standard production (Fig. 31). Designed bed carrier plate was converted to $2 \mathrm{D}$ with CATIA drafting module the design, which was formed according to the selected bed unit connection nests and holes, was formed by a plasma-cutting device. Plasma cutting process time was 1.5 minutes and CAD data provides benefits in the production process and in performing modifications in a short time (Fig. 32).

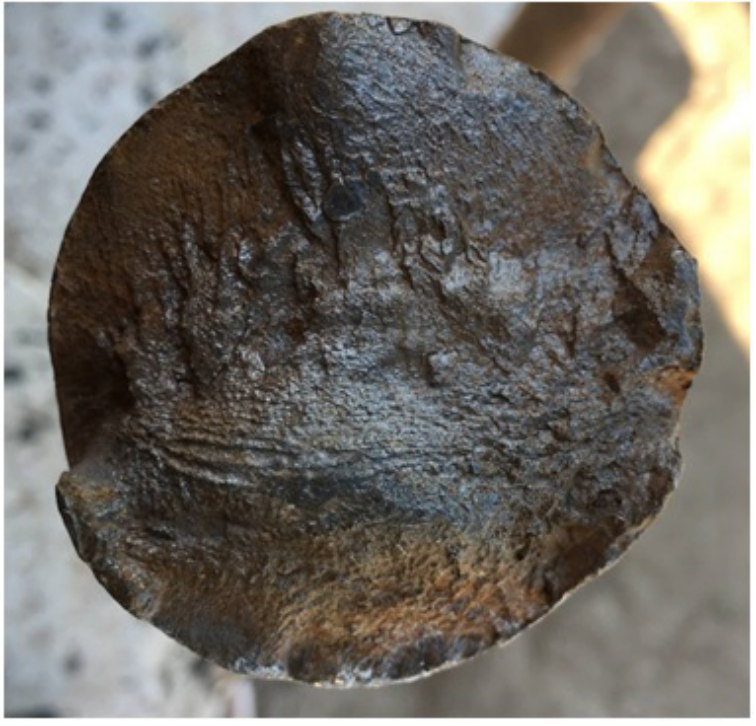

Fig. 30. The beach remarks of fatigue damage

The system design was completed in 6 hours, including the assembly process (Fig. 33).

- Forming the roller axle design with the methodical construction principles prevented the complexity during design and shortened the design period.

- Field work was evaluated. It was concluded that the systematic construction targets determined for the design were chosen appropriately.

- The weight of the cut plate is $14 \mathrm{~kg}$. Bearing unit weight is $3.8 \mathrm{~kg}$. The total weight of the anti-fatigue healing design with the bolts is $20 \mathrm{~kg}$.

- The methodical solution in this study provided reaching the ultimate goal in the shortest time both simply and successfully. Furthermore, modularity also provides benefits such as determining the design of the damaged area, disappearance of uncalculated details that do not appear in the production process. Not using the methodical solution in the construction is the biggest mistake and is the main reason for the failure and the missed solution chance $[4,10]$.

- The use of computer aided engineering minimizes the time spent in the design of complex $3 \mathrm{D}$ models and the risks involved in the manu-

Table 2. Comparison of the first working case of the shaft with the performed design

\begin{tabular}{|c|c|c|c|c|}
\hline & $\begin{array}{c}\text { Max Von mises Stress } \\
\text { Reduction [\%] }\end{array}$ & $\begin{array}{c}\text { Maksimum Total Defor- } \\
\text { mation Reduction [\%] }\end{array}$ & $\begin{array}{c}\text { Fatigue Life Increase } \\
{[\%]}\end{array}$ & $\begin{array}{c}\text { Safety Factor Increase } \\
{[\%]}\end{array}$ \\
\hline $\begin{array}{c}\text { Rate of change } \\
\text { the system. }\end{array}$ & 62.23 & 88.34 & 746.02 & 164.61 \\
\hline
\end{tabular}




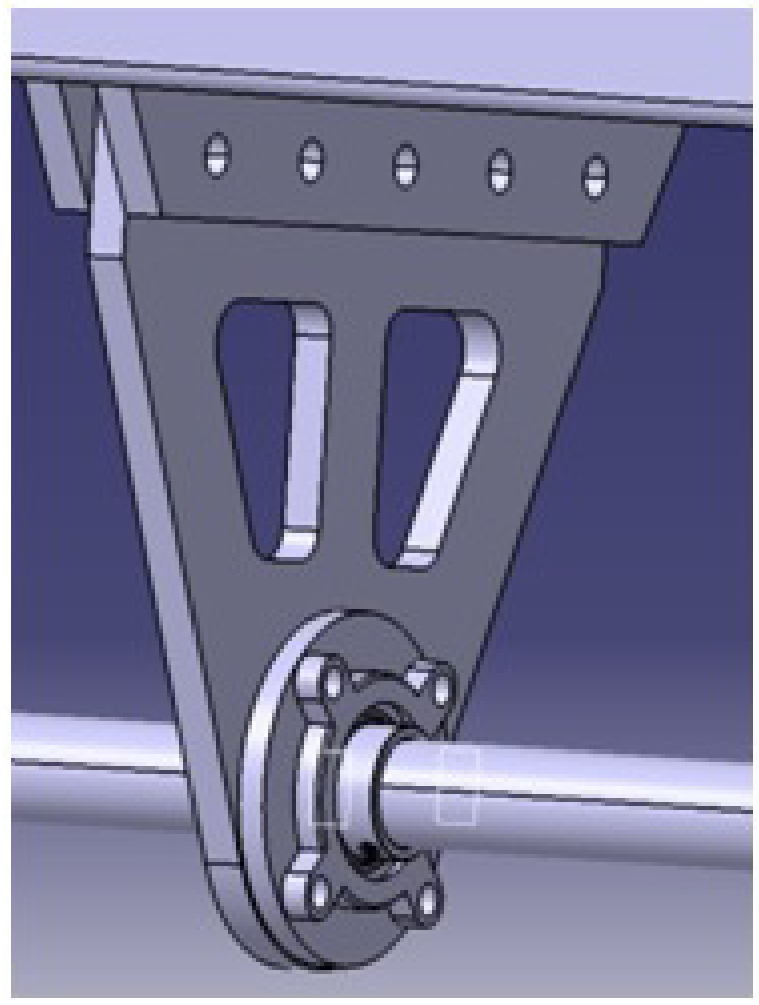

Fig. 31. Shaft modular bearing design

facturing process. Ansys software calculates the systems that a person cannot calculate and it shortens the time with respect to mathematical methods that a person can calculate. [12]. Design is an important activity that determines the quality of the product [15].

\section{CONCLUSION}

1. By adding only $20 \mathrm{~kg}$ of additional bearing design to a system with a weight of $1400 \mathrm{~kg}$ and subjected to shaft fatigue damage, the tension strength under normal conditions was reduced from 131.79 $\mathrm{MPa}$ to $49.8 \mathrm{MPa}$. The fatigue strength increased from 118200 to $1 \times 106$ infinite life limits.

2. In the re-design study, the occurred damage was removed within 6 hours of operation, including production and installation.

3. Re-design operation uses a bolted connection. It does not show an obstacle in the sense of modularity. Modularity benefits the economy in the sense that an existing system can be used for different purposes.

4. The new design was carried out with CATIA. CATIA is an effective program for the emergence of new and complex designs.

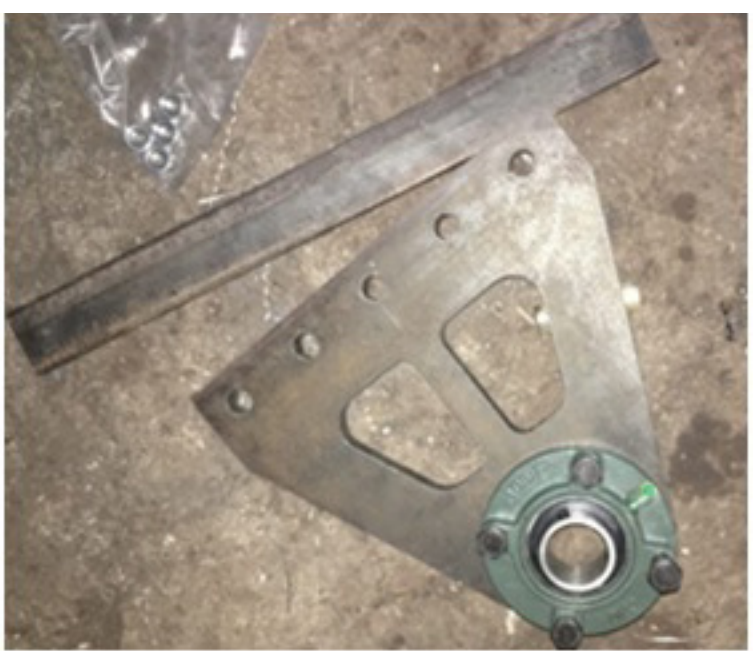

Fig. 32. Production of design

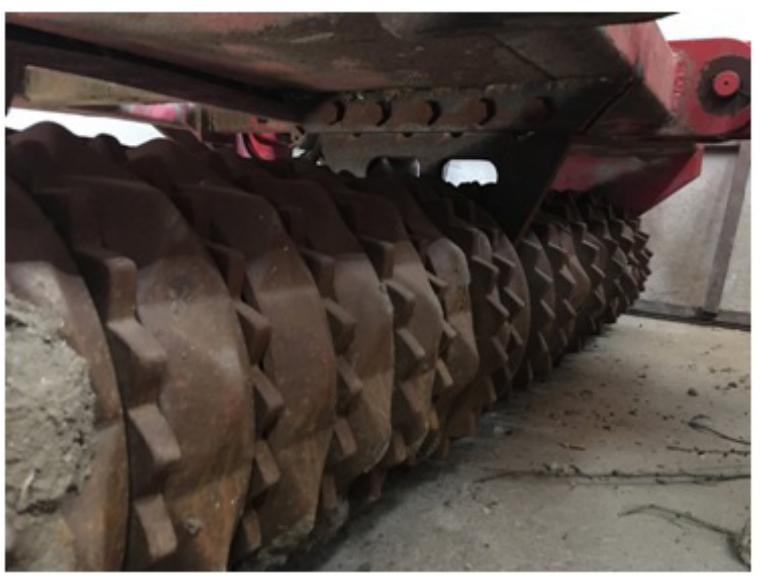

Fig. 33. The system as a result of shaft modular bearing design installation and field tests

5. The results of the Ansys dynamic fatigue analysis are consistent with the cycles of usage of the damaged shaft.

6. In the system where the damaged shaft is examined, the roller units are in lateral contact with each other. However, in this anti-fatigue system, a $25 \mathrm{~mm}$ line in the bearing section remains un-pressed in the middle section. It has been seen that this is something to be ignored in field study.

7. Fatigue deformation does not progress linearly on the fracture surface.

8. The fracture surface contains depth in ductile fatigue. In the case of fatigue damage of brittle materials, there is almost no depth along the axis of the shaft.

9. The design was used on 560.000 cycles and damage did not occur. 


\section{REFERENCES}

1. Osi O.: Fatigue Failure Of A Rear Axle Shaft Of An Automobile, Engineering Failure Analysis, 13, 2006, 1293-1302.

2. Basnet A., Rajgadia S., Karki A., Das D., Jaiswal P., Jaiswal R., Jha A.R., Barman R.N.: Design And Analysis Of Solid Crank Shaft Using Catia And Ansys Workbench, International Journal Of Advanced Research İn Biology Engineering Science And Technology, 2, 2016, 86-99.

3. Budynas R.G., Nisbett J. K.: Shigley's Mechanical Engineering Design, Eighth Edition in SI Units, 2016.

4. Cavdar K., Babalik C.F.: Methodic In Designing Hydraulic Systems Using Construction Principles, Iii. National Hydraulic Pneumatic Congress And Exhibition, 2003, 377-387.

5. Espadafor F.J., Villanueva J.B., García M.T.: Analysis Of A Diesel Generator Crankshaft Failure, Engineering Failure Analysis, 16, 2009, 2333-2341.

6. Fonte M., Reis L., Romeiro F., Li B., Freitas M, The Effect Of Steady Torsion On Fatigue Crack Growth In Shafts, International Journal Of Fatigue, 28, 2016, 609-617.

7. Goksenli A., Eryurek I.B.: Failure Analysis Of An Elevator Drive Shaft, Engineering Failure Analysis, 16, 2009, 1011-1019.

8. Hasan S.G.A., Kumar G.S., Fatima S.S.: Finite Element Analysis And Fatigue Analysıs Of Spur Gear Under Random Loading, Finite Element Analysis And Fatigue Analysis Of Spur Gear Under Random Loadıng, 4, 2015, 523-534.

9. Jha A., Jaiswal R., Karki A., Basnet A., Jaiswal P., Rajgadia S., Das D., Barman R.N.: Design And Finite Element Analysis Of Knuckle Joint Using Catıa And Ansys Workbench, International Journal Of Research In Mechanical Engineering, 4, 2016, 1-5.

10. Kutay G.: http://www.guven-kutay.ch/

11. Li W., Yan Q., Xue J.: Analysis Of A Crankshaft Fatigue Failure, Engineering Failure Analysis, 55, 2015, 139-147.
12. Panda S., Behera D.N., Tripathy S.N.: Modelıng And Structural Analysis Of Alloy Wheel Using Ansys, International Journal Of Engıneerıng Sciences \& Research Technology, 5, 3, 2016, 467-474.

13. Panda S.S., Gurung J., Chatterjee U.K., Sahoo S.: Modelıng-And-Fatıgue-Analysis-Of- AutomotıveWheel-Rim, International Journal Of Engineering Sciences \& Research Technology, 5, 2016, 428-435.

14. Parkash O., Gupta V., Mittal V.: Optimizing The Design Of Connecting Rod Under Static And Fatigue Loading, International Journal Of Research İn Management, Science \& Technology, 1, 2013, 39-43.

15. Prasad T.S., Krishnaiah T., Iliyas J.M., Reddy M.J.: A Review On Modeling And Analysis Of Car WheelRim Using Catıa \& Ansys, International Journal Of Innovative Science And Modern Engineering (Ij1sme), 2, 2014, 1-5.

16. Shelke S.S., Dhamejani C.L., Gadhave A.S.: Modeling And Analysis Of The Crankshaft Using Ansys Software, International Journal Of Engineering Science And Computing, 6, 2016, 6796-6800.

17. Singh A, Soni V., Singh A.: Structural Analysis of Ladder Chassis for Higher Strength, International Journal of Emerging Technology and Advanced Engineering, 4, 2014, 253-259.

18. Talikoti B.S., Kurbet S.N., Kuppast V.V.: Statıc Structural Analysis of 2-Cylinder Crankshaft Using Ansys, International Journal For Technological Research In Engineering, 3, 2015, 242-245.

19. Thriveni K., Chandraiah B.J.: Modeling And Analysis Of The Crankshaft Using Ansys Software, International Journal Of Computational Engineering Research, 3, 2013, 84-89.

20. Vogwell J.: Analysis Of A Vehicle Wheel Shaft Fa1lure, Engineering Failure Analysis, 5, 1998, 2071-2077.

21. Yao W., Ye B., Zheng L.: A Verification Of The Assumption Of Anti-Fatigue Design, International Journal Of Fatigue, 23, 2001, 271-277.

22. Zangeneh S., Ketabchi M., Kalaki A.: Fracture Failure Analysis Of A1s1 3041 Stainless Steel Shaft, Engineering Failure Analysis, 36, 2014, 155-165. 